\title{
Contribution of ultra-processed foods in the diet of adults from the French NutriNet-Santé study
}

\author{
Chantal Julia ${ }^{1,2, *}$, Lucien Martinez ${ }^{1}$, Benjamin Allès ${ }^{1}$, Mathilde Touvier ${ }^{1}$, \\ Serge Hercberg ${ }^{1,2}$, Caroline Méjean ${ }^{1}$ and Emmanuelle Kesse-Guyot ${ }^{1}$ \\ 'Université Paris 13, Equipe de Recherche en Epidémiologie Nutritionnelle (EREN), Centre d'Epidemiologie et \\ Biostatistiques Sorbonne Paris Cité (CRESS), Inserm U1 153, Inra U1 125, Cnam, COMUE Sorbonne-Paris-Cité, \\ 74 rue Marcel Cachin, F-93017 Bobigny Cedex, France: ${ }^{2}$ Département de Santé Publique, Hôpital Avicenne \\ (AP-HP), F-93017 Bobigny Cedex, France
}

Submitted 6 October 2016: Final revision received 19 May 2017: Accepted 25 May 2017: First published online 13 July 2017

\begin{abstract}
Objective: Concerns have been raised about the potential health impact of ultra-processed foods (UPF) in the diet. Our objective was to investigate the contribution of UPF in the diet in a large French population and its association with sociodemographic factors and dietary patterns.

Design: Cross-sectional analysis of dietary data from 74470 participants in the web-based NutriNet-Santé cohort. UPF were identified in repeated $24 \mathrm{~h}$ records and the proportion (in weight) of UPF in the total diet (UPFp) was computed for each participant. Associations of sociodemographic characteristics and UPFp in quartiles were assessed using multivariate multinomial logistic regression. Food group consumption and nutrient intakes across quartiles of UPFp were estimated using linear regression adjusted for sociodemographic factors and energy intake. Setting: France.

Results: UPF contributed $18.4 \%$ of the foods consumed in weight and $35.9 \%$ of total energy intake. Higher UPFp consumption was independently associated with male gender, younger age, lower education, smoking, and overweight and obesity (all $P<0.0001$ ). Participants in the highest UPFp quartile consumed lower amounts of fruit and vegetables (difference between quartile 4 and quartile 1 of UPFp, $\Delta=-180.3 \mathrm{~g} / \mathrm{d})$ and higher amounts of sweet products $(\Delta=68.5 \mathrm{~g} / \mathrm{d})$ and soft drinks $(\Delta=98.6 \mathrm{~g} / \mathrm{d}$; all $P<0.0001)$. They had higher intakes of energy $(\Delta=610 \mathrm{~kJ} / \mathrm{d}(145.7 \mathrm{kcal} / \mathrm{d}))$ and added sugar $(\Delta=17 \cdot 1 \mathrm{~g} / \mathrm{d})$, and lower intakes of fibre $(\Delta=-4.04 \mathrm{~g} / \mathrm{d}), \beta$-carotene $(\Delta=-1019 \cdot 6 \mu \mathrm{g} / \mathrm{d})$ and $\mathrm{Ca}(\Delta=-87.8 \mathrm{mg} / \mathrm{d}$; all $P<0 \cdot 0001)$.

Conclusions: UPF represent an important part of the diet in adults from the French general population and are associated with unbalanced nutritional intakes.
\end{abstract}

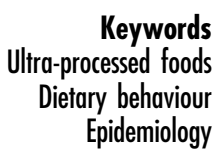

Non-communicable diseases represent a major public health challenge to Western countries, in part related to the continuing rise in the prevalence in obesity and overweight in the last decades ${ }^{(1,2)}$. The rising trend of these diseases has been accompanied by a concomitant rise in the share of processed foods in the diet ${ }^{(3,4)}$. Processed foods are defined considering the series of technological modifications they undergo to increase their safety, shelf-life or palatability ${ }^{(5)}$. Some processes such as canning (in salt or oil) or fermenting have long been integrated in the food supply. However, technological innovations in recent years have prompted a wide range of novel processes, leading to the development and dissemination of ultra-processed foods (UPF). Several degrees in the processing of foods have therefore been identified $^{(6,7)}$, with UPF being industrial formulations and represented by manufactured convenient and intensely palatable 'ready-to-eat' foods ${ }^{(8,9)}$. In Western countries, global industrial systems dominate the food supply, generating an important availability of these $\mathrm{UPF}^{(9)}$. As such, UPF are widespread in the food supply, including in 'healthy' food groups such as fruits and vegetables (e.g. as pre-packaged soups). Dietary guidelines in Western countries, such as France, essentially refer to food group consumption in their disseminated booklets ${ }^{(10,11)}$. They promote the consumption of certain food groups (e.g. fruit and vegetables) and the limitation of others. Recommendations pertain, for example, to the limitation of certain foods with high content of fat, sugar or salt. Rising concern 
about the potential impact of UPF on health has, however, prompted some governments to take action and incorporate this novel dimension of foods within their dietary guidelines ${ }^{(12)}$. Indeed, UPF have been found to be associated to obesity and metabolic syndrome in recent studies ${ }^{(13-15)}$.

UPF have been described as higher in energy, saturated fat, sugar and sodium, and lower in nutrients ${ }^{(8,9)}$. Thus, diets rich in UPF usually exhibit high contents of sugar, lipids, saturated fats and sodium ${ }^{(16)}$. As such, they are thought to be potential drivers for both obesity and metabolic syndrome ${ }^{(17-19)}$. Beyond this nutritional aspect, processing itself is suggested to degrade the structure and characteristics of the original food, which could lead to adverse health effects $^{(20,21)}$. Finally, UPF usually include additives (including colours and flavours) and use fractioning and recombining of food ingredients. However, dietary patterns according to the amount of UPF in the diet have only recently been described in Western countries, namely the UK, the USA and Canada ${ }^{(7,16,19,22,23)}$, where they account for more than $50 \%$ of the energy intake of the population.

The large range of available UPF in Western countries, as well as the development of UPF with 'balanced' dietary profiles (such as pre-packaged whole meals or non-sugared flavoured water), suggests that they may also be included in diets adhering to dietary guidelines, given that the processing dimension of foods is not used in dietary guidelines to define 'healthy' diets. Moreover, as 'healthy' alternatives within UPF represent a driver for industrial growth, their share within 'healthy' diets could be more important than expected $^{(24)}$. Given that dietary guidelines focus exclusively on consumption of food groups, using a broad definition of these groups, individuals considered to have high adherence to dietary guidelines could also have high consumption of UPF. As such, compliance with dietary guidelines based on conventional definition of food groups would not necessarily represent optimal diets, since grouping would lump foods from various levels of processing.

Our objective was to investigate the proportion of UPF in the diet in a large sample from the French general population included in the NutriNet-Santé study. We aimed at describing the diet according to the level of UPF in the diet. Moreover, we aimed at investigating the relative contribution of each food group, as defined according to dietary guidelines, to the proportion of UPF in the overall study and in a subgroup of individuals with high adherence to nutritional recommendations. These latter analyses aimed at investigating whether dietary guidelines as they are currently defined would be consistent or not with optimal diets in terms of processing.

\section{Materials and methods}

\section{Population}

The NutriNet-Santé cohort study has previously been described in detail ${ }^{(25)}$. Briefly, its objective is to study the relationships between nutrition (combining diet and physical activity) and health and to investigate the determinants of dietary behaviour, using a large sample of more than 100000 volunteers.

The NutriNet-Santé study is conducted according to the Declaration of Helsinki guidelines, and was approved by the Institutional Review Board of the French Institute for Health and Medical Research (IRB Inserm no. 0000388FWA00005831) and the 'Commission Nationale de l'Informatique et des Libertés' (CNIL no. 908450 and 909216). Electronic informed consent was obtained from each participant (EudraCT no. 2013-000929-31).

\section{Data collection}

At baseline and annually thereafter, using a secured webbased interface, participants have to answer questionnaires pertaining to their dietary habits ( $24 \mathrm{~h}$ records), health, sociodemographic characteristics, anthropometrics and physical activity. Additional questionnaires pertaining to determinants of dietary behaviour or risk exposure are regularly proposed in the study. In the present study, individuals who were included up to June 2014 and had completed three $24 \mathrm{~h}$ records at inclusion were eligible for participation. Individuals residing outside mainland France or with missing information about covariates (smoking status, physical activity or sociodemographic characteristics) were excluded.

\section{Diet}

At inclusion in the NutriNet-Santé study, participants have to fulfil three $24 \mathrm{~h}$ dietary records. The days for the records were selected at random in a two-week period, with one weekend day and two weekdays. The participants were asked to estimate the portion size for each reported food and beverage item using validated photographs ${ }^{(26)}$. Items in the database reflect usually consumed foods in the French diet ${ }^{(27)}$. The food database contains more than 3000 foods. During the completion of the record, participants have the possibility (optional) to indicate if the food was from a specific brand or home-prepared. Food group classification was computed by taking account of the classification of foods used in French dietary guidelines ${ }^{(10,11)}$. Noteworthy, for this classification, the contribution of food items to each food group is decomposed; for example, for ready-to-eat meals, vegetables contained in the meal contribute to the overall vegetable consumption. Nutrient intake was computed using a validated food composition table ${ }^{(27)}$. Under-reporters for energy intake were excluded using the Black method ${ }^{(28)}$. Validation studies comparing the web-based dietary questionnaires with interviews by dietitians or biomarkers of nutritional status and with measured data (for anthropometry) showed a good validity of the collected data ${ }^{(29-32)}$.

\section{Food processing}

Each food item in the food composition table of the NutriNet-Santé study (3022 foods and beverages) was 
categorized as ultra-processed or not based on the NOVA classification $^{(6,7)}$. This categorization was performed by a team of three dietitians trained in nutritional epidemiology, supervised by researchers. Home-made and artisanal foods (including artisanal breads) were identified and decomposed using standardized recipes, and the classification was applied to their ingredients. In case of uncertainty, consensus was reached among the researchers. To help identifying home-made and artisanal foods, researchers and dietitians relied on the percentage of reported brand products consumed.

\section{Covariates}

Sociodemographic data were collected at baseline using self-administered questionnaires. Sex, age $(<25$ years, 25-44 years, 45-64 years, $\geq 65$ years), education ( $<12$ years, 12 years, $13-15$ years, $>15$ years of education), marital status (in couple, single/divorced/widowed), income per household unit $^{(33)} \quad(<1200 € /$ month, 1200-2300 €/month, $>2300 € /$ month), residence (rural, urban) and smoking status (current smoker, former smoker, never smoker) were collected.

Physical activity level was computed using self-declared data from the International Physical Activity Questionnaire, completed at baseline (low, moderate, high) ${ }^{(34)}$.

Self-reported weight and height were collected at baseline and were used to compute BMI (WHO categories: $<18.5 \mathrm{~kg} / \mathrm{m}^{2}, \quad 18.5-24.9 \mathrm{~kg} / \mathrm{m}^{2}, \quad 25.0-29.9 \mathrm{~kg} / \mathrm{m}^{2}$, $\left.\geq 30 \cdot 0 \mathrm{~kg} / \mathrm{m}^{2}\right)^{(35)}$.

\section{Statistical analysis}

The proportion (in weight, g/d) of UPF in the total diet (UPFp) was computed for each participant. Weight was considered to take better account of non-nutritional issues pertaining to processing of foods (e.g. neo-formed contaminants and alterations to the structure of raw foods). For comparison with international data, the proportion in energy of UPF was also computed (termed energyweighted UPFp).

Associations between quartiles of UPFp and sociodemographic characteristics were estimated using multivariable multinomial logistic regression and mutually adjusted percentages for each sociodemographic category were computed. Food group consumption and nutrient intakes across quartiles of UPFp were investigated using multivariable linear regression adjusted for sociodemographic variables and energy intake. Nutrient intakes were adjusted for energy intake using the residual method $^{(36)}$. $P$ values for trend were computed using quartiles as continuous variables in the multivariable linear regressions.

The adherence to French nutritional recommendations was evaluated using the PNNS-GS (Programme National Nutrition Santé Guideline Score) ${ }^{(37)}$. Briefly, the PNNS-GS allocates points to participants for each of the thirteen PNNS recommendations on diet and physical activity.
A penalty is attributed for excess energy intake ${ }^{(37)}$. This a priori score has been validated in a French cohort and serves as a reference score for the nutritional quality of the diet $^{(37)}$. UPFp and PNNS-GS were partitioned in quartiles for analyses.

Participants in the fourth quartile of the PNNS-GS, reflecting healthier diets ('Healthy' group), were selected for a specific subgroup analysis to determine the importance of UPF in individuals with healthier lifestyles.

In both the overall sample and the 'Healthy' subgroup, the contribution of UPF from each food group was investigated across population-specific quartiles of UPFp using multivariable linear regressions adjusted for sociodemographic variables, energy intake and PNNS-GS for residual confounding. All analyses were replicated using energy-weighted UPFp.

All tests were two-sided and a $P$ value $<0.001$ was considered significant, given the high number of statistical tests performed. Statistical analyses were performed using the statistical software package SAS version 9.3.

\section{Results}

Among the 95942 individuals having three dietary records available at baseline, 74470 had no missing data on sociodemographic, BMI and lifestyle data and were therefore included in the present study. The total sample was mainly female ( $77 \%$ of the total sample), with a mean age of 43.8 (SD 14.4) years. Overall, UPF represented $18.4 \%$ of the total amount of foods consumed by weight, and $35.9 \%$ of total energy intake (data not shown). The Pearson correlation coefficient between quantity-weighted UPFp and energy-weighted UPFp was 0.69.

A higher consumption of UPF was independently associated with male gender, younger age, lower income, lower level of education, smoking, and overweight and obesity (all $P<0.0001$; see Table 1). Similar results were obtained when using energy-weighted UPFp (see online supplementary material, Supplemental Table 1). Compared with participants in the lowest quartile of UPFp, those in the highest quartile (consuming more than $23 \%$ of their foods as UPF) consumed lower amounts of fruit and vegetables (difference between quartile 4 and quartile 1 of UPFp, $\quad \Delta=-180.3 \mathrm{~g} / \mathrm{d})$, dairy products $(\Delta=-21.8 \mathrm{~g} / \mathrm{d})$ and beverages $(\Delta=-462.9 \mathrm{~g} / \mathrm{d})$, mainly tea, coffee or water $(\Delta=-591.5 \mathrm{~g} / \mathrm{d}$; all $P<0 \cdot 0001$; Table 2$)$. Conversely, they consumed higher amounts of sugary products $(\Delta=68.5 \mathrm{~g} / \mathrm{d})$ and soft drinks $(\Delta=98.6 \mathrm{~g} / \mathrm{d}$; all $P<0.0001$; Table 2). Similar results were obtained when using energyweighted UPFp (see Supplemental Table 2).

Compared with participants in the lowest quartile of UPF, those in the highest quartile had an overall less balanced diet, as expressed by the PNNS-GS $(\Delta=-1.51$ points). In terms of nutrient intakes, they had higher energy intake $(\Delta=610 \mathrm{~kJ} / \mathrm{d}(145.7 \mathrm{kcal} / \mathrm{d}))$, with higher 
Table 1 Sociodemographic characteristics according to the proportion of ultra-processed food (UPFp) in the diet of adults from the French NutriNet-Santé cohort $(n 74470)$

\begin{tabular}{|c|c|c|c|c|c|}
\hline \multirow[b]{3}{*}{ Variable } & \multicolumn{4}{|c|}{ UPFp in the diet } & \multirow[b]{3}{*}{$P$ value } \\
\hline & \multirow{2}{*}{$\frac{\text { Quartile 1 }}{<0.11}$} & \multirow{2}{*}{$\frac{\text { Quartile 2 }}{0.11-0.16}$} & \multirow{2}{*}{$\frac{\text { Quartile 3 }}{0.16-0.23}$} & \multirow{2}{*}{$\frac{\text { Quartile 4 }}{\geq 0.23}$} & \\
\hline & & & & & \\
\hline$n$ & 18617 & 18618 & 18618 & 18617 & 74470 \\
\hline \multicolumn{6}{|l|}{ Sex } \\
\hline Men & $16 \cdot 8$ & $18 \cdot 6$ & $18 \cdot 9$ & $21 \cdot 7$ & \\
\hline Women & $83 \cdot 2$ & 81.4 & $81 \cdot 1$ & $78 \cdot 3$ & $<0.0001$ \\
\hline \multicolumn{6}{|l|}{ Age (years) } \\
\hline$<25$ & 1.2 & $2 \cdot 1$ & $3 \cdot 2$ & 5.9 & \\
\hline $25-44$ & 25.4 & $32 \cdot 9$ & $39 \cdot 2$ & 51.4 & \\
\hline $45-64$ & $63 \cdot 3$ & $56 \cdot 1$ & $49 \cdot \overline{6}$ & 37.5 & \\
\hline$\geq 65$ & $10 \cdot 0$ & 8.9 & 8.0 & $5 \cdot 2$ & $<0.0001$ \\
\hline \multicolumn{6}{|c|}{ Income per household unit ( $€ /$ month) } \\
\hline$<1200$ & 27.5 & $25 \cdot 9$ & $26 \cdot 5$ & $28 \cdot 1$ & \\
\hline $1200-1799$ & $35 \cdot 1$ & $36 \cdot 3$ & $36 \cdot 6$ & $37 \cdot 2$ & \\
\hline $1800-2299$ & $16 \cdot 2$ & $16 \cdot 8$ & $16 \cdot 9$ & $16 \cdot 2$ & \\
\hline$\geq 2300$ & $21 \cdot 2$ & 21.0 & $20 \cdot 0$ & 18.5 & $<0.0001$ \\
\hline \multicolumn{6}{|l|}{ Marital status } \\
\hline Single/divorced/widowed & $30 \cdot 6$ & $29 \cdot 7$ & $30 \cdot 4$ & $34 \cdot 1$ & \\
\hline Married/cohabiting & 69.5 & $70 \cdot 3$ & 69.7 & $66 \cdot 0$ & $<0.0001$ \\
\hline \multicolumn{6}{|l|}{ Educational level (years) } \\
\hline$<12$ & $2 \cdot 0$ & $2 \cdot 0$ & $2 \cdot 1$ & $2 \cdot 8$ & \\
\hline 12 & 38.6 & $40 \cdot 1$ & $42 \cdot 1$ & $46 \cdot 7$ & \\
\hline $13-15$ & 31.8 & $32 \cdot 1$ & $31 \cdot 0$ & $30 \cdot 2$ & \\
\hline$>15$ & $27 \cdot 6$ & $25 \cdot 8$ & 24.8 & $20 \cdot 3$ & $<0.0001$ \\
\hline \multicolumn{6}{|l|}{ Residence } \\
\hline Rural & $18 \cdot 3$ & 18.6 & $18 \cdot 8$ & $17 \cdot 5$ & \\
\hline Urban & $81 \cdot 8$ & 81.5 & $81 \cdot 2$ & 82.5 & 0.12 \\
\hline \multicolumn{6}{|l|}{ Smoking status } \\
\hline Never smoker & $49 \cdot 0$ & $52 \cdot 4$ & $53 \cdot 2$ & $52 \cdot 9$ & \\
\hline Former smoker & $35 \cdot 3$ & $32 \cdot 6$ & $32 \cdot 1$ & $30 \cdot 7$ & \\
\hline Current smoker & $15 \cdot 6$ & $15 \cdot 1$ & $14 \cdot 7$ & $16 \cdot 4$ & $<0.0001$ \\
\hline \multicolumn{6}{|l|}{$\mathrm{BMI}\left(\mathrm{kg} / \mathrm{m}^{2}\right)$} \\
\hline$<18.5$ & $3 \cdot 0$ & $2 \cdot 6$ & $2 \cdot 6$ & $2 \cdot 9$ & \\
\hline $18.5-24.9$ & $64 \cdot 0$ & 63.9 & $62 \cdot 1$ & $59 \cdot 8$ & \\
\hline $25 \cdot 0-29 \cdot 9$ & 24.9 & $25 \cdot 3$ & $26 \cdot 1$ & 25.9 & \\
\hline
\end{tabular}

Percentages are mutually adjusted using multivariable logistic regression.

energy intakes from carbohydrates and lipids $(\Delta=1 \cdot 33 \%$ and $\Delta=0.79 \%$ of energy intake without alcohol) and lower energy intake from protein $(\Delta=-2 \cdot 12 \%$ of energy intake without alcohol; Table 3). They had also lower intakes of fibre $(\Delta=-4.04 \mathrm{~g} / \mathrm{d}), \quad \beta$-carotene $(\Delta=-1019 \cdot 6 \mu \mathrm{g} / \mathrm{d})$, Ca $(\Delta=-87.8 \mathrm{mg} / \mathrm{d})$, vitamin $\mathrm{C}(\Delta=-22.8 \mathrm{mg} / \mathrm{d})$ and folic acid $(\Delta=-55.6 \mu \mathrm{g} / \mathrm{d})$, and higher intake of added sugar ( $\Delta=17 \cdot 1 \mathrm{~g} / \mathrm{d}$; Table 3$)$. Similar results were obtained when using energy-weighted UPFp (see Supplemental Table 3).

The proportion of consumption of each food group, using the conventional dietary guidelines approach, in the total amount of UPF varied greatly across quartiles of UPFp (Table 4). In particular, the contribution of sugary products to UPF consumption decreased from $27.9 \%$ in quartile 1 of UPFp to $18.8 \%$ in quartile 4 , while the contribution of beverages to UPF consumption increased from $10.8 \%$ in the first quartile to $30.5 \%$ in the fourth quartile (mainly from soft drinks, which contributed from 2.5 to $13 \cdot 2 \%)$. The highest contributors to UPF consumption were confectionery, chocolate and dairy desserts (20.0\%), fruit and vegetables (12.7\%), biscuits and cakes (7.8\%), and pasta, rice and bread (7.0\%) in quartile 1 ; they were confectionery, chocolate and dairy desserts (13.3\%), soft drinks (13.2\%) and fruit and vegetables (11.8\%) in quartile 4 . When using energy-weighted UPFp, the major contributors were confectionery (28.7\%) and biscuits and cakes (13.8\%; see Supplemental Table 4). The profiles of contributors were similar between the first and fourth quartiles of energy-weighted UPFp (see Supplemental Table 4).

In the 'Healthy' group (i.e. participants with a high adherence to nutritional recommendations, based on the PNNS-GS), the proportion of UPF was $14.3 \%$ of the total amount of foods. It varied between less than $9 \%$ in the first quartile to more than $19 \%$ in the last quartile (Table 5). In this group, the contribution of confectionery, chocolate and dairy decreased between the quantile 1 and quartile 4 of UPFp from 19.7 to $10 \cdot 8 \%$, while the contribution of vegetables increased from 8.7 to $13.8 \%$ and the contribution of tea, coffee and water increased from 3.6 to $11.2 \%$ (Table 5). When using energy-weighted UPFp, profiles of contributors were similar across quartiles of 
Table 2 Food consumption ( $\mathrm{g} / \mathrm{d}$ ) according to the proportion of ultra-processed food (UPFp) in the diet of adults from the French NutriNet-Sante cohort $(n 74470)$

\begin{tabular}{|c|c|c|c|c|c|c|c|c|c|}
\hline \multirow[b]{4}{*}{ Food group } & \multicolumn{8}{|c|}{ UPFp in the diet } & \multirow[b]{4}{*}{$P$ for trend } \\
\hline & \multirow{2}{*}{\multicolumn{2}{|c|}{$\begin{array}{c}\text { Quartile } 1 \\
<0.11\end{array}$}} & \multirow{2}{*}{\multicolumn{2}{|c|}{$\begin{array}{l}\text { Quartile } 2 \\
0 \cdot 11-0 \cdot 16\end{array}$}} & \multirow{2}{*}{\multicolumn{2}{|c|}{$\frac{\text { Quartile 3 }}{0.16-0.23}$}} & \multirow{2}{*}{\multicolumn{2}{|c|}{$\begin{array}{c}\text { Quartile } 4 \\
\geq 0.23\end{array}$}} & \\
\hline & & & & & & & & & \\
\hline & Mean & SD & Mean & SD & Mean & SD & Mean & SD & \\
\hline Fruits and vegetables & $507 \cdot 8$ & $255 \cdot 7$ & $440 \cdot 4$ & $216 \cdot 4$ & $401 \cdot 2$ & $205 \cdot 9$ & $327 \cdot 4$ & $200 \cdot 3$ & $<0.0001$ \\
\hline Fruits & 251.9 & 181.5 & 208.7 & 149.5 & $181 \cdot 1$ & $136 \cdot 7$ & 138.5 & $126 \cdot 7$ & $<0.0001$ \\
\hline Vegetables & 255.9 & $135 \cdot 2$ & $231 \cdot 7$ & 120.6 & $220 \cdot 1$ & 118.4 & 188.9 & 118.0 & $<0.0001$ \\
\hline Meat, fish and eggs & $146 \cdot 1$ & $75 \cdot 1$ & 139.5 & $70 \cdot 0$ & 133.0 & 69.2 & 124.6 & $70 \cdot 0$ & $<0.0001$ \\
\hline Meat and poultry & 82.9 & $58 \cdot 3$ & 83.9 & $56 \cdot 4$ & 82.5 & $56 \cdot 7$ & 82.7 & 58.5 & $<0.0001$ \\
\hline Fish and seafood & $47 \cdot 3$ & $48 \cdot 8$ & 41.4 & $43 \cdot 8$ & $37 \cdot 1$ & 41.9 & 29.8 & 37.3 & $<0.0001$ \\
\hline Eggs & $15 \cdot 9$ & $23 \cdot 7$ & $14 \cdot 3$ & 21.8 & $13 \cdot 4$ & $20 \cdot 9$ & $12 \cdot 0$ & $19 \cdot 8$ & $<0.0001$ \\
\hline Processed meat & $17 \cdot 7$ & 23.9 & $22 \cdot 7$ & $28 \cdot 2$ & 24.9 & 30.5 & $26 \cdot 5$ & $32 \cdot 7$ & $<0.0001$ \\
\hline Fats & 24.9 & $16 \cdot 8$ & $25 \cdot 7$ & $16 \cdot 9$ & $26 \cdot 1$ & $17 \cdot 2$ & $25 \cdot 2$ & $17 \cdot 6$ & 0.06 \\
\hline Sugary products & 94.2 & $68 \cdot 7$ & 125.9 & $79 \cdot 1$ & $143 \cdot 3$ & 89.1 & $162 \cdot 8$ & $101 \cdot 8$ & $<0.0001$ \\
\hline Dried fruit & 3.0 & $10 \cdot 9$ & 2.6 & 8.6 & $2 \cdot 3$ & 7.9 & 1.8 & $7 \cdot 3$ & $<0.0001$ \\
\hline Biscuits and cakes & $38 \cdot 4$ & $45 \cdot 5$ & 49.6 & $50 \cdot 2$ & 54.8 & $54 \cdot 1$ & $60 \cdot 2$ & $56 \cdot 9$ & $<0.0001$ \\
\hline $\begin{array}{l}\text { Confectionery, chocolate, dairy desserts } \\
\text { and other sugary products }\end{array}$ & $52 \cdot 8$ & $47 \cdot 8$ & $73 \cdot 7$ & $58 \cdot 8$ & $86 \cdot 2$ & $67 \cdot 6$ & $100 \cdot 9$ & $81 \cdot 2$ & $<0.0001$ \\
\hline Salty snacks & 13.9 & 20.4 & $15 \cdot 6$ & $20 \cdot 0$ & $16 \cdot 4$ & 20.5 & $17 \cdot 5$ & 22.4 & $<0.0001$ \\
\hline Dairy products & $211 \cdot 0$ & $162 \cdot 7$ & 204.7 & $152 \cdot 7$ & $199 \cdot 7$ & 153.7 & $189 \cdot 2$ & 154.4 & $<0.0001$ \\
\hline Cheese & $36 \cdot 8$ & 30.8 & 37.4 & 29.8 & 37.3 & 29.7 & 36.0 & 30.1 & $<0.0001$ \\
\hline Milk & $77 \cdot 8$ & $129 \cdot 3$ & 81.4 & $125 \cdot 2$ & 84.4 & $126 \cdot 5$ & 85.5 & 123.7 & 0.002 \\
\hline Yoghurt and cottage cheese & $96 \cdot 4$ & 99.6 & $85 \cdot 8$ & 89.5 & $78 \cdot 0$ & 87.6 & $67 \cdot 7$ & 89.0 & $<0.0001$ \\
\hline Starchy foods & 246.5 & 115.5 & 249.2 & $108 \cdot 4$ & 247.9 & $108 \cdot 1$ & 241.3 & $105 \cdot 9$ & $<0.0001$ \\
\hline Whole grains & $42 \cdot 0$ & 55.9 & $36 \cdot 8$ & 49.9 & 33.7 & 48.8 & $28 \cdot 1$ & 44.9 & $<0.0001$ \\
\hline Pasta, rice and bread & $142 \cdot 7$ & 94.1 & $146 \cdot 5$ & 89.5 & $146 \cdot 1$ & 88.3 & 143.4 & 84.9 & $<0.0001$ \\
\hline Potatoes and tubers & $57 \cdot 1$ & $59 \cdot 6$ & 59.5 & 58.3 & 60.5 & $57 \cdot 1$ & 60.9 & $57 \cdot 0$ & 0.013 \\
\hline Breakfast cereals & 4.7 & $14 \cdot 0$ & $6 \cdot 4$ & $16 \cdot 3$ & 7.5 & $17 \cdot 7$ & 8.9 & $20 \cdot 0$ & $<0.0001$ \\
\hline Beverages & 1556.5 & 651.9 & $1398 \cdot 1$ & 559.2 & $1262 \cdot 3$ & 513.5 & 1093.5 & 493.7 & $<0.0001$ \\
\hline Alcoholic beverages & 114.5 & $177 \cdot 3$ & $110 \cdot 3$ & $166 \cdot 8$ & 97.6 & 151.5 & 77.0 & $137 \cdot 1$ & $<0.0001$ \\
\hline Light sodas & 0.2 & 4.3 & 0.4 & $7 \cdot 1$ & 0.8 & 11.2 & 2.5 & 24.7 & $<0.0001$ \\
\hline Tea, coffee and water & 1379.8 & 635.8 & $1201 \cdot 0$ & 531.3 & $1050 \cdot 1$ & 469.3 & 788.4 & 428.7 & $<0.0001$ \\
\hline Vegetable milk & 2.5 & $16 \cdot 1$ & 6.9 & 31.7 & $15 \cdot 1$ & 56.9 & $55 \cdot 1$ & $160 \cdot 5$ & $<0.0001$ \\
\hline Soft drinks & $10 \cdot 8$ & 38.5 & $21 \cdot 7$ & $50 \cdot 1$ & 38.5 & $71 \cdot 2$ & $109 \cdot 4$ & $175 \cdot 3$ & $<0.0001$ \\
\hline Fruit and vegetable juice & $48 \cdot 6$ & $79 \cdot 4$ & $57 \cdot 7$ & $85 \cdot 7$ & $60 \cdot 2$ & $86 \cdot 5$ & $61 \cdot 1$ & 90.9 & $<0.0001$ \\
\hline Other & 39.6 & 38.4 & 54.8 & $49 \cdot 6$ & $67 \cdot 1$ & 60.5 & $72 \cdot 3$ & 71.9 & $<0.0001$ \\
\hline
\end{tabular}

Adjusted for sex, age, educational level, income, marital status, smoking status, BMl classification and energy intake. $P$ values for trend obtained with multivariable linear regression using quartiles as continuous variables.

UPF and similar in the 'Healthy' group to the entire sample (see Supplemental Table 5).

\section{Discussion}

Our results show that, in France, UPF contribute an important amount to consumption, accounting for about $35.9 \%$ of energy intake and $18.4 \%$ of the amount consumed, and $45.4 \%$ of energy intake and $23.8 \%$ of the amount consumed when taking processed foods (Group 3.1) into account.

This proportion of energy intake from UPF is lower than what has been observed in other Western countries ${ }^{(7,22)}$. Indeed, international data from representative dietary surveys or per capita consumption data suggest that UPF contribute an average of $53 \%$ in the $\mathrm{UK}^{(22)}, 57.9 \%$ of energy intake in the USA ${ }^{(7)}$ and up to $61.7 \%$ in Canada ${ }^{(19)}$. The proportion of energy-weighted UPF in our sample appears to be between what has been observed in developing countries such as Brazil $(29 \cdot 6 \%)^{(23)}$ and the proportion observed in Western countries ${ }^{(7,22)}$. France still holds a widespread dietary culture that has been recognized internationally by $\mathrm{UNESCO}^{(38)}$ and includes some norms concerning home-made cooking, promotion of whole foods and social gatherings for family meals. Moreover, some typical foods that are consumed in large amounts, such as bread, are consumed mainly from artisanal bakeries, rather than from industrial pre-packaged foods. These features might explain the lower proportion of UPF observed in our sample compared with other Western countries.

The UPFp variable that we used in the main analyses considers the proportion, in weight, of UPF in the diet. Such weighing tends to give a lower importance to energy-dense foods, which may be consumed in lower amounts but contribute importantly to energy intakes, and a higher importance to beverages and low-energy foods (e.g. vegetables), consumed in higher amounts. Given the higher energy density of UPF, such weighting lowers the 
Table 3 Nutrient intake according to the proportion of ultra-processed food (UPFp) in the diet of adults from the French NutriNet-Santé cohort ( $n$ 74 470)

\begin{tabular}{|c|c|c|c|c|c|c|c|c|c|}
\hline \multirow[b]{4}{*}{ Nutrient } & \multicolumn{8}{|c|}{ UPFp in the diet } & \multirow[b]{4}{*}{$P$ for trend } \\
\hline & \multirow{2}{*}{\multicolumn{2}{|c|}{$\begin{array}{c}\text { Quartile } 1 \\
<0.11\end{array}$}} & \multirow{2}{*}{\multicolumn{2}{|c|}{$\begin{array}{l}\text { Quartile } 2 \\
0 \cdot 11-0 \cdot 16\end{array}$}} & \multirow{2}{*}{\multicolumn{2}{|c|}{$\frac{\text { Quartile } 3}{0.16-0.23}$}} & \multirow{2}{*}{\multicolumn{2}{|c|}{$\begin{array}{c}\text { Quartile } 4 \\
\geq 0.23\end{array}$}} & \\
\hline & & & & & & & & & \\
\hline & Mean & SD & Mean & SD & Mean & SD & Mean & SD & \\
\hline PNNS-GS & 8.48 & 1.64 & $8 \cdot 00$ & 1.64 & $7 \cdot 64$ & 1.64 & $6 \cdot 98$ & 1.69 & $<0.0001$ \\
\hline Energy intake (alcohol excluded; $\mathrm{kJ} / \mathrm{d}$ ) & 7385 & 1879 & 7757 & 1942 & 7883 & 2015 & 7996 & 2123 & $<0.0001$ \\
\hline Energy intake (alcohol excluded; kcal/d) & 1765 & 449.0 & 1854 & $464 \cdot 2$ & 1884 & 481.5 & 1911 & 507.5 & $<0.0001$ \\
\hline Energy from carbohydrates (\%) & 42.41 & 7.69 & $42 \cdot 88$ & 6.84 & 43.20 & $6 \cdot 72$ & 43.75 & 6.89 & $<0.0001$ \\
\hline Energy from lipids (\%) & 38.97 & $7 \cdot 18$ & 39.41 & $6 \cdot 49$ & 39.57 & $6 \cdot 41$ & $39 \cdot 76$ & $6 \cdot 42$ & $<0.0001$ \\
\hline Energy from protein (\%) & $18 \cdot 62$ & 4.50 & $17 \cdot 72$ & 3.84 & $17 \cdot 23$ & $3 \cdot 76$ & $16 \cdot 50$ & 3.84 & $<0.0001$ \\
\hline Alcohol $(\mathrm{g} / \mathrm{d})$ & $9 \cdot 72$ & $13 \cdot 68$ & 9.08 & $13 \cdot 14$ & 7.94 & $12 \cdot 24$ & $6 \cdot 22$ & 11.55 & $<0.0001$ \\
\hline Sugar $(\mathrm{g} / \mathrm{d})$ & 89.57 & $26 \cdot 32$ & $91 \cdot 72$ & 24.94 & 93.82 & $25 \cdot 28$ & 98.73 & 28.04 & $<0.0001$ \\
\hline Added sugar $(\mathrm{g} / \mathrm{d})$ & 30.56 & $16 \cdot 65$ & 35.72 & $17 \cdot 78$ & 39.52 & $19 \cdot 02$ & 47.66 & $24 \cdot 22$ & $<0.0001$ \\
\hline Added fats $(\mathrm{g} / \mathrm{d})$ & $25 \cdot 24$ & $12 \cdot 08$ & 23.94 & 11.62 & $23 \cdot 15$ & 11.53 & $22 \cdot 01$ & 11.54 & $<0.0001$ \\
\hline Added animal fat $(\mathrm{g} / \mathrm{d})$ & 8.45 & 7.51 & 8.40 & $7 \cdot 35$ & $8 \cdot 27$ & $7 \cdot 26$ & 7.49 & $7 \cdot 11$ & 0.28 \\
\hline Added vegetable fat $(\mathrm{g} / \mathrm{d})$ & $16 \cdot 81$ & 10.68 & $15 \cdot 56$ & $10 \cdot 17$ & 14.91 & $10 \cdot 02$ & 14.56 & $10 \cdot 16$ & $<0.0001$ \\
\hline SFA $(g / d)$ & $32 \cdot 15$ & 8.07 & 33.28 & 7.87 & 33.83 & 7.88 & $34 \cdot 11$ & $8 \cdot 11$ & $<0.0001$ \\
\hline MUFA (g/d) & $31 \cdot 16$ & 7.94 & $30 \cdot 76$ & $7 \cdot 12$ & 30.56 & $6 \cdot 91$ & $30 \cdot 65$ & 6.89 & $<0.0001$ \\
\hline PUFA (g/d) & 11.82 & 4.82 & 11.63 & 4.49 & 11.58 & 4.41 & 11.65 & 4.44 & 0.012 \\
\hline$n-3$ fatty acids $(\mathrm{g} / \mathrm{d})$ & 1.56 & 0.90 & 1.44 & 0.81 & 1.35 & 0.76 & 1.21 & 0.71 & $<0.0001$ \\
\hline$n-6$ fatty acids $(\mathrm{g} / \mathrm{d})$ & 9.60 & 4.45 & 9.53 & 4.16 & 9.56 & $4 \cdot 10$ & 9.75 & $4 \cdot 18$ & 0.37 \\
\hline Cholesterol $(\mathrm{g} / \mathrm{d})$ & 320.09 & $128 \cdot 74$ & 319.39 & 124.77 & $315 \cdot 16$ & $122 \cdot 59$ & $305 \cdot 25$ & $120 \cdot 23$ & 0.03 \\
\hline Fibres $(g / d)$ & 21.81 & $6 \cdot 80$ & $20 \cdot 32$ & 6.38 & 19.48 & $6 \cdot 24$ & $17 \cdot 77$ & 6.52 & $<0.0001$ \\
\hline $\mathrm{Na}(\mathrm{g} / \mathrm{d})$ & 2691.43 & 691.96 & 2733.45 & $697 \cdot 61$ & 2755.99 & $718 \cdot 14$ & 2691.24 & $736 \cdot 29$ & $<0.0001$ \\
\hline$\beta$-Carotene $(\mu \mathrm{g} / \mathrm{d})$ & 3991.48 & 3160.96 & $3635 \cdot 80$ & $2732 \cdot 33$ & 3409.71 & 2523.01 & 2971.92 & $2527 \cdot 36$ & $<0.0001$ \\
\hline Vitamin $C(\mathrm{mg} / \mathrm{d})$ & 131.54 & 76.52 & 121.01 & 69.38 & 115.95 & 90.06 & $108 \cdot 71$ & 81.44 & $<0.0001$ \\
\hline Folic acid $(\mu \mathrm{g} / \mathrm{d})$ & $360 \cdot 82$ & 118.49 & 339.75 & $106 \cdot 53$ & 328.51 & $103 \cdot 84$ & $305 \cdot 24$ & $105 \cdot 81$ & $<0.0001$ \\
\hline Vitamin $B_{12}(\mu \mathrm{g} / \mathrm{d})$ & 5.85 & 6.09 & 5.35 & $5 \cdot 13$ & 5.09 & 4.81 & 4.74 & 4.47 & $<0.0001$ \\
\hline $\mathrm{Ca}(\mathrm{mg} / \mathrm{d})$ & 974.52 & $268 \cdot 89$ & 943.43 & 254.72 & $927 \cdot 31$ & 255.53 & $886 \cdot 73$ & $268 \cdot 21$ & $<0.0001$ \\
\hline Vitamin $D(\mu \mathrm{g} / \mathrm{d})$ & 2.98 & 2.56 & $2 \cdot 79$ & $2 \cdot 24$ & 2.66 & $2 \cdot 13$ & 2.48 & $2 \cdot 12$ & $<0.0001$ \\
\hline
\end{tabular}

PNNS-GS, Programme National Nutrition Santé Guideline Score.

Adjusted for sex, age, educational level, income, marital status, smoking status, BMI classification and energy intake using the residual method. $P$ values for trend obtained with multivariable linear regression using quartiles as continuous variables.

total amount of UPF in the diet. The construction of the individual variable based on weight was elected for several reasons. Indeed, beyond their nutritional characteristics, UPF also exhibit higher levels of neo-formed contaminants resulting from heat processing ${ }^{(20,39)}$. Such contaminants (e.g. acrylamide or furans) are considered potentially carcinogenic in $\operatorname{man}^{(40-42)}$. Moreover, UPF are suggested to be less satiating than minimally processed foods, due in particular to the alteration of the food matrix through fractioning and recombining of ingredients ${ }^{(21)}$, which could also be associated with the higher energy intake observed in diets rich in UPF. As both the presence of neo-formed contaminants and the satiety characteristics of UPF are likely more related to the total amount consumed rather than the energy density of foods, we considered that weight was a relevant variable to include in the exposure to UPF. Finally, a weighting based on energy intake from foods structurally discounts beverages with artificial sweeteners, which are highly processed foods but do not contribute to energy intakes. This is particularly apparent when considering the food groups contributing to the amounts consumed $v$. energy intakes. When using energy-weighted UPFp, major contributors were energydense foods, such as confectionery, chocolate, biscuits and cakes (contributing almost $50 \%$ of the energy intake from UPF), while beverages contributed only less than $6 \%$. When using quantity-weighted UPFp, the contribution of the same energy-dense groups of foods decreased to $23 \%$, while the contribution of beverages (particularly soft drinks) increased to $18 \%$. More importantly, while the profile of food groups contributing to energy intake did not appear to vary according to the nutritional quality of the diet, it did vary when taking the amounts consumed into account. Especially non-sugared beverages contributed a high level to the quantity of foods consumed in the 'Healthy' group (up to $11 \%$ ), mainly from artificially sweetened flavoured water or tea, which was not apparent when using energyweighted UPFp.

The proportion of UPF consumed in the diet varied widely according to sociodemographic profile. UPF consumption was more particularly associated with younger age and an overall lower socio-economic profile, objectifying social inequalities in food choice. UPF are widely available in Western countries ${ }^{(9)}$ and constitute affordable ready-to-eat options, which can appeal to individuals with lower budgets or lower nutritional knowledge ${ }^{(17)}$.

Consumption of UPF was also associated with a lower overall balance of the diet, with higher intakes of salty, 
Table 4 Contribution (\%) of each food group to the proportion of ultra-processed food (UPFp) in the diet of adults from the French NutriNet-Santé cohort ( $n$ 74470)

\begin{tabular}{|c|c|c|c|c|c|c|c|c|c|}
\hline \multirow[b]{4}{*}{ Food group } & \multicolumn{8}{|c|}{ UPFp in the diet } & \multirow[b]{4}{*}{$P$ for trend } \\
\hline & \multirow{2}{*}{\multicolumn{2}{|c|}{$\begin{array}{c}\text { Quartile } 1 \\
<0.11\end{array}$}} & \multirow{2}{*}{\multicolumn{2}{|c|}{$\frac{\text { Quartile 2 }}{0.11-0.16}$}} & \multirow{2}{*}{\multicolumn{2}{|c|}{$\begin{array}{l}\text { Quartile } 3 \\
0.16-0.23\end{array}$}} & \multirow{2}{*}{\multicolumn{2}{|c|}{$\begin{array}{c}\text { Quartile } 4 \\
\geq 0.23\end{array}$}} & \\
\hline & & & & & & & & & \\
\hline & Mean & $\mathrm{SD}$ & Mean & SD & Mean & SD & Mean & SD & \\
\hline Fruits and vegetables & $12 \cdot 7$ & $14 \cdot 4$ & 14.5 & $12 \cdot 9$ & $14 \cdot 7$ & $12 \cdot 4$ & 11.8 & $10 \cdot 8$ & $<0.0001$ \\
\hline Fruits & 4.3 & 9.9 & 4.2 & 7.9 & 4.0 & 7.0 & 3.0 & 5.5 & 0.001 \\
\hline Vegetables & 8.4 & 11.3 & $10 \cdot \overline{3}$ & $10 \cdot 7$ & $10 \cdot 8$ & 10.5 & 8.8 & $9 \cdot 0$ & $<0.0001$ \\
\hline Meat, fish and eggs & $7 \cdot 4$ & $10 \cdot 6$ & $6 \cdot 2$ & 6.9 & $5 \cdot 5$ & 5.7 & 4.8 & 4.6 & $<0.0001$ \\
\hline Meat and poultry & $6 \cdot 2$ & $10 \cdot 1$ & $4 . \overline{9}$ & $6 \cdot 3$ & 4.3 & $5 \cdot 1$ & 3.7 & $4 \cdot 1$ & $<0.0001$ \\
\hline Fish and seafood & 1.0 & 3.4 & 1.0 & $2 \cdot 8$ & 1.0 & $2 \cdot 4$ & 0.8 & 1.9 & 0.46 \\
\hline Eggs & 0.3 & 0.9 & 0.3 & 0.7 & 0.2 & 0.6 & 0.2 & 0.5 & $<0.0001$ \\
\hline Processed meat & 6.6 & $10 \cdot 3$ & $5 \cdot 1$ & $7 \cdot 2$ & 4.3 & 5.9 & 3.3 & 4.6 & $<0.0001$ \\
\hline Fats & $2 \cdot 8$ & 4.5 & $2 \cdot 3$ & $2 \cdot 7$ & $2 \cdot 2$ & $2 \cdot 2$ & 1.7 & 1.7 & $<0.0001$ \\
\hline Sugary products & 27.9 & $20 \cdot 6$ & $24 \cdot 4$ & $16 \cdot 7$ & 22.0 & 14.9 & $18 \cdot 8$ & 13.1 & $<0.0001$ \\
\hline Dried fruit & 0.1 & $1 \cdot 1$ & 0.1 & 0.8 & 0.1 & 0.5 & 0.0 & 0.4 & $<0.0001$ \\
\hline Biscuits and cakes & 7.8 & $10 \cdot 9$ & 6.9 & $8 \cdot 1$ & $6 \cdot 2$ & $7 \cdot 0$ & 5.4 & $6 \cdot 1$ & $<0.0001$ \\
\hline $\begin{array}{l}\text { Confectionery, chocolate, dairy desserts } \\
\text { and other sugary products }\end{array}$ & 20.0 & $18 \cdot 2$ & $17 \cdot 4$ & $14 \cdot 6$ & $15 \cdot 7$ & $12 \cdot 9$ & $13 \cdot 3$ & $11 \cdot 2$ & $<0.0001$ \\
\hline Salty snacks & $2 \cdot 3$ & 4.8 & 2.0 & 3.5 & 1.8 & 3.0 & 1.6 & 2.5 & $<0.0001$ \\
\hline Dairy products & 5.6 & 11.6 & $7 \cdot 0$ & 11.3 & $7 \cdot 1$ & $10 \cdot 4$ & 6.7 & 9.2 & $<0.0001$ \\
\hline Cheese & 1.6 & 3.8 & 1.6 & 2.9 & 1.5 & 2.5 & 1.5 & $2 \cdot 2$ & $<0.0001$ \\
\hline Milk & 0.5 & $3 \cdot 2$ & 0.7 & $3 \cdot 2$ & 0.8 & 3.6 & 1.0 & 4.1 & $<0.0001$ \\
\hline Yoghurt and cottage cheese & 3.5 & $10 \cdot 7$ & 4.8 & 10.7 & 4.8 & $9 \cdot 7$ & 4.2 & $8 \cdot 1$ & $<0.0001$ \\
\hline Starchy foods & $15 \cdot 6$ & $14 \cdot 8$ & 14.8 & $11 \cdot 1$ & $14 \cdot 2$ & 9.8 & $12 \cdot \overline{9}$ & 8.6 & $<0.0001$ \\
\hline Whole grains & $2 \cdot 8$ & $7 \cdot 0$ & 1.9 & 4.5 & 1.6 & 3.8 & 1.3 & $3 \cdot 1$ & $<0.0001$ \\
\hline Pasta, rice and bread & 7.0 & $10 \cdot 4$ & $7 \cdot 0$ & 8.5 & 6.8 & 7.5 & 6.3 & 6.5 & $<0.0001$ \\
\hline Potatoes and tubers & 3.6 & $7 \cdot 3$ & $4 \cdot 1$ & $6 \cdot 0$ & 4.3 & $5 \cdot 3$ & 4.0 & 4.7 & $<0.0001$ \\
\hline Breakfast cereals & $2 \cdot 3$ & $7 \cdot 0$ & 1.7 & 4.5 & 1.6 & 3.7 & 1.3 & $2 \cdot 9$ & $<0.0001$ \\
\hline Beverages & 10.8 & $17 \cdot 0$ & $14 \cdot 7$ & $17 \cdot 8$ & 18.6 & $19 \cdot 1$ & 30.5 & 22.5 & $<0.0001$ \\
\hline Alcoholic beverages & 3.5 & 8.5 & $3 \cdot 2$ & $7 \cdot 3$ & $2 \cdot 8$ & $6 \cdot 4$ & $2 \cdot 2$ & 5.9 & $<0.0001$ \\
\hline Light sodas & 0.1 & 1.5 & 0.1 & 1.6 & 0.2 & 1.9 & 0.3 & $2 \cdot 8$ & $<0.0001$ \\
\hline Tea, coffee and water & $2 \cdot 8$ & $10 \cdot 0$ & 3.6 & $10 \cdot 8$ & 4.5 & $12 \cdot 2$ & 6.5 & $15 \cdot 3$ & $<0.0001$ \\
\hline Vegetable milk & 1.0 & 5.9 & 1.7 & 7.5 & $2 \cdot 7$ & 9.3 & $6 \cdot 0$ & 14.5 & $<0.0001$ \\
\hline Soft drinks & 2.5 & $9 \cdot 0$ & 4.4 & $10 \cdot 6$ & $6 \cdot 6$ & $12 \cdot 2$ & $13 \cdot 2$ & 17.9 & $<0.0001$ \\
\hline Fruit and vegetable juice & 1.0 & 5.9 & 1.6 & $6 \cdot 6$ & $2 \cdot 0$ & $6 \cdot 7$ & $2 \cdot 2$ & $6 \cdot 6$ & $<0.0001$ \\
\hline Other & 8.2 & $10 \cdot 1$ & 9.0 & 9.9 & 9.5 & 9.9 & 8.0 & 8.7 & $<0.0001$ \\
\hline
\end{tabular}

PNNS-GS, Programme National Nutrition Santé Guideline Score.

Percentages are adjusted for sex, age, educational level, income, marital status, smoking status, BMI classification, energy intake and PNNS-GS. $P$ values for trend obtained with multivariable linear regression using quartiles as continuous variables.

fatty and sugary products, leading to higher intakes of added sugar and SFA and lower intakes of vitamins and minerals. Even in individuals with high adherence to nutritional guidelines, the proportion of UPF consumed varied considerably. However, the profile of foods contributing to UPFp consumption was different from the overall sample, as they included more fruit and vegetables and whole grains. These results tend to confirm the dual associations between the processing and nutritional dimensions of foods.

The main contributors to UPFp (in quantity) in our study were sugary products (accounting for $23.3 \%$ of total UPFp), mainly confectionery (16.6\%); followed by starchy foods (14.4\%), mainly bread, pasta and rice (6.8\%); and fruit and vegetables $(13.4 \%)$, mainly vegetables (9.5\%). Soft drinks contributed $6.7 \%$ of total UPFp; however, they were one of the main drivers for the difference between low consumers (quartile 1) and high consumers (quartile 4) of UPFp (contribution from $2.5 \%$ in the first quartile to $13.2 \%$ in the last quartile). These results are consistent to some extent with the main contributors to UPF consumption observed in other settings. Indeed, in the study by Moubarac et al. set in Canada, bread was the main contributor to UPF consumption, followed by confectionery and soft drinks ${ }^{(19)}$. In the study from Steele et al. set in the USA, the main contributors were breads and soft drinks ${ }^{(7)}$. Finally, in the study from Louzada et al., set in Brazil, the main contributors were bread ( $9.2 \%$ of total energy intake), pizzas, hamburger and sandwiches ( $4.7 \%)$, and cakes and cookies $(3.0 \%)^{(23)}$. The main differences observed in our setting appear to reside in the difference of UPFp from bread and fruit and vegetables. Indeed, in France, bread is mostly consumed from artisanal bakeries and as such does not contribute to UPF consumption. As for fruit and vegetables, our results show that fruit and vegetables from ready-to-eat meals or prepackaged ultra-processed products contribute importantly to their overall consumption.

However, these results tend to suggest some form of homogenization of dietary patterns across countries in terms 
Table 5 Contribution (\%) of each food group to the proportion of ultra-processed food (UPFp) in the diet in the 'Healthy' group of adults from the French NutriNet-Santé cohort ( $n$ 18167)

\begin{tabular}{|c|c|c|c|c|c|c|c|c|c|}
\hline \multirow[b]{5}{*}{ Food group } & \multicolumn{8}{|c|}{ UPFp in the diet } & \multirow[b]{5}{*}{$P$ for treno } \\
\hline & \multirow{2}{*}{\multicolumn{2}{|c|}{$\begin{array}{c}\text { Quartile } 1 \\
n 4541\end{array}$}} & \multirow{2}{*}{\multicolumn{2}{|c|}{$\begin{array}{c}\text { Quartile } 2 \\
n 4542\end{array}$}} & \multicolumn{2}{|c|}{ Quartile 3} & \multicolumn{2}{|c|}{ Quartile 4} & \\
\hline & & & & & & & \multicolumn{2}{|c|}{$n 4542$} & \\
\hline & \multicolumn{2}{|c|}{$<0.09$} & \multicolumn{2}{|c|}{$0.09-0.13$} & \multicolumn{2}{|c|}{$0.13-0.19$} & \multicolumn{2}{|c|}{$\geq 0.19$} & \\
\hline & Mean & SD & Mean & SD & Mean & SD & Mean & SD & \\
\hline Fruits and vegetables & $13 \cdot 9$ & $16 \cdot 7$ & $17 \cdot 1$ & $15 \cdot 0$ & $18 \cdot 7$ & $14 \cdot 4$ & $19 \cdot 0$ & 13.9 & $<0.0001$ \\
\hline Fruits & $5 \cdot 1$ & $12 \cdot 0$ & 5.5 & $10 \cdot 1$ & $5 \cdot 3$ & 8.9 & $5 \cdot 2$ & $8 \cdot 2$ & 0.05 \\
\hline Vegetables & 8.7 & $12 \cdot 8$ & 11.6 & $12 \cdot 2$ & $13 \cdot 3$ & $12 \cdot 1$ & $13 \cdot 8$ & $11 . \overline{5}$ & $<0.0001$ \\
\hline Meat, fish and eggs & $7 \cdot 6$ & 11.5 & $6 \cdot 0$ & 7.4 & $5 \cdot 3$ & 5.9 & $4 \cdot 2$ & 4.8 & $<0.0001$ \\
\hline Meat and poultry & $6 \cdot 4$ & 11.0 & 4.7 & $6 \cdot 7$ & 4.0 & $5 \cdot 2$ & 3.1 & 4.3 & $<0.0001$ \\
\hline Fish and seafood & 1.0 & $3 \cdot 7$ & 1.1 & $3 \cdot 1$ & 1.0 & $2 \cdot 8$ & 0.9 & $2 \cdot 2$ & 0.46 \\
\hline Eggs & 0.2 & 0.9 & 0.2 & 0.6 & 0.2 & 0.5 & 0.1 & 0.4 & $<0.0001$ \\
\hline Processed meat & $5 \cdot 6$ & $10 \cdot 3$ & 4.2 & 6.9 & 3.3 & $5 \cdot 2$ & $2 \cdot 3$ & 3.7 & $<0.0001$ \\
\hline Fats & 3.2 & 5.5 & 2.6 & 2.9 & $2 \cdot 4$ & $2 \cdot 3$ & $2 \cdot 1$ & 1.9 & $<0.0001$ \\
\hline Sugary products & $27 \cdot 1$ & $21 \cdot 7$ & $22 \cdot 1$ & $16 \cdot 4$ & $18 \cdot 7$ & 13.9 & 14.5 & 11.5 & $<0.0001$ \\
\hline Dried fruit & 0.1 & 1.6 & 0.1 & 0.8 & 0.1 & 0.8 & 0.1 & 0.6 & 0.06 \\
\hline Biscuits and cakes & $7 \cdot 2$ & $11 \cdot 3$ & 5.6 & $7 \cdot 6$ & 4.7 & $6 \cdot 0$ & 3.6 & 4.8 & $<0.0001$ \\
\hline $\begin{array}{l}\text { Confectionery, dairy desserts } \\
\text { and other sugary products }\end{array}$ & $19 \cdot \overline{7}$ & $19 \cdot 4$ & $16 \cdot 4$ & 14.6 & 13.9 & $12 \cdot 4$ & $10 \cdot 8$ & $10 \cdot 3$ & $<0.0001$ \\
\hline Salty snacks & 1.9 & 4.7 & 1.6 & $3 \cdot 3$ & 1.3 & $2 \cdot 7$ & 0.9 & 2.0 & $<0.0001$ \\
\hline Dairy products & 5.6 & $12 \cdot 8$ & $7 \cdot 7$ & 13.3 & 8.1 & $12 \cdot 7$ & 8.2 & 11.5 & $<0.0001$ \\
\hline Cheese & 1.5 & $4 \cdot 3$ & 1.3 & $2 \cdot 8$ & 1.2 & $2 \cdot 2$ & 1.0 & 1.9 & $<0.0001$ \\
\hline Milk & 0.5 & 3.5 & 0.7 & 3.7 & 0.9 & 4.0 & 0.9 & 3.9 & $<0.0001$ \\
\hline Yoghurt and cottage cheese & 3.7 & 11.7 & 5.6 & $12 \cdot 8$ & $6 \cdot 1$ & $12 \cdot 0$ & $6 \cdot 3$ & $10 \cdot 9$ & $<0.0001$ \\
\hline Starchy foods & $16 \cdot 6$ & $16 \cdot 8$ & $15 \cdot 2$ & $12 \cdot 4$ & $14 \cdot 3$ & $10 \cdot 4$ & 12.5 & 8.9 & $<0.0001$ \\
\hline Whole grains & 4.3 & $9 \cdot 7$ & 2.9 & $6 \cdot 2$ & $2 \cdot 6$ & $5 \cdot 3$ & $2 \cdot 3$ & 4.4 & $<0.0001$ \\
\hline Pasta, rice and bread & $6 \cdot 4$ & $11 \cdot 0$ & $6 \cdot 1$ & $8 \cdot 6$ & 5.7 & 7.5 & 4.7 & $6 \cdot 0$ & $<0.0001$ \\
\hline Potatoes and tubers & 3.1 & 7.1 & 3.9 & $6 \cdot 1$ & 4.1 & $5 \cdot 2$ & 4.1 & 4.6 & $<0.0001$ \\
\hline Breakfast cereals & 2.9 & 8.9 & $2 \cdot 2$ & $5 \cdot 7$ & 1.9 & 4.5 & 1.5 & 3.3 & $<0.0001$ \\
\hline Beverages & $10 \cdot 1$ & 17.9 & $14 \cdot 2$ & 18.9 & 16.9 & $19 \cdot 8$ & $25 \cdot 0$ & 23.5 & $<0.0001$ \\
\hline Alcoholic beverages & 2.9 & $8 \cdot 3$ & 2.5 & $6 \cdot 4$ & $2 \cdot 1$ & 5.4 & 1.5 & $4 \cdot 1$ & $<0.0001$ \\
\hline Light sodas & 0.1 & 1.4 & 0.1 & 1.9 & 0.2 & $2 \cdot 3$ & 0.3 & $2 \cdot 7$ & 0.002 \\
\hline Tea, coffee and water & 3.6 & $12 \cdot 0$ & $5 \cdot 2$ & 13.5 & 6.5 & 14.7 & 11.2 & 19.4 & $<0.0001$ \\
\hline Vegetable milk & 0.9 & $6 \cdot 0$ & 1.5 & 7.4 & 2.6 & $9 \cdot 3$ & 6.0 & $15 \cdot 3$ & $<0.0001$ \\
\hline Soft drinks & 1.7 & 7.8 & 3.0 & $9 \cdot 4$ & 3.6 & 9.4 & 3.7 & 8.6 & $<0.0001$ \\
\hline Fruit and vegetable juice & 1.0 & $6 \cdot 2$ & $1 \cdot 7$ & $7 \cdot 3$ & 1.9 & $7 \cdot 1$ & $2 \cdot 3$ & $7 \cdot 1$ & $<0.0001$ \\
\hline Other & 8.2 & $10 \cdot 7$ & 9.3 & $10 \cdot 3$ & 11.0 & $10 \cdot 8$ & $11 \cdot 2$ & $10 \cdot 2$ & $<0.0001$ \\
\hline
\end{tabular}

PNNS-GS, Programme National Nutrition Santé Guideline Score.

Adjusted for sex, age, educational level, income, marital status, smoking status, BMI classification, energy intake and PNNS-GS. $P$ values for trend obtained with multivariable linear regression using quartiles as continuous variables.

of UPF consumption. UPF usually correspond to high-energydensity ready-to-eat convenience foods, consumption of which increases rapidly along with the nutrition transition in both developed and developing countries ${ }^{(43)}$. Most UPF are representative of the global food system delivered by transnational 'Big Food' companies that operate on a global scale (PepsiCo $^{\circledR}$ and Coca-Cola ${ }^{\circledR}$ are examples of such companies $)^{(17,44,45)}$. The foods these companies produce are somewhat representative of the 'Western' diet, high in fat, sugar and sodium, that represents a trend towards globalization of diets at the world level ${ }^{(45)}$. The fact that contributors to UPF consumption should appear overall consistent across countries tends to reflect this shift from traditional diets towards a more uniform Western diet. This contention is supported by the sociodemographic profiles we observed in high UPF consumers. UPF consumption is associated with younger age, objectifying a somewhat generational shift from traditional food patterns to more Westernized patterns.
A general assumption is that individuals adhering to nutritional recommendations would have lower consumption of UPF. Some studies even suggest that diets containing UPF cannot meet nutritional recommendations ${ }^{(19)}$. However, in our study, although the proportion of UPF in the diet was much lower in the 'Healthy' group (9.5 v. $18.4 \%$ in the overall sample), it still exhibited a wide range and accounted for up to $>19 \%$ of the total amount consumed in this group (v. $21 \%$ in the overall sample). These findings suggest that it is indeed possible to have both a high adherence to dietary guidelines and a high consumption of UPF, as dietary guidelines focus on consumption of food groups, using a broad nutritional definition, and do not take account of their type of processing. Moreover, though UPF typically include so-called 'junk' foods, they are ubiquitous in the food supply in Western countries and are therefore largely present in 'healthy' food groups such as whole grains or fruit and 
vegetables (e.g. ready-to-eat vegetable purée or soups). Therefore, considering these divergent dimensions of foods (the nutritional and the processing dimensions), fruit and vegetables from ready-to-eat ultra-processed products still contribute to overall fruit and vegetable consumption according to the dietary guidelines definition. Moreover, the production of 'healthy' processed foods - such as UPF enriched in micronutrients or reformulated industrial products - is one of the drivers for growth in market share for food companies ${ }^{(24,46)}$. As such, it is noteworthy that the contribution of fruit and vegetables to UPFp is higher in the 'Healthy' group.

These results may appear a challenge to public health initiatives. Overall, our results tend to show that dietary guidelines, using only conventional definitions of food groups, may not lead to optimal diets since they do not consider the extent and purpose of processing. Therefore, taking the processing dimension of foods into account may be of major importance within nutritional recommendations. Indeed, dietary guidelines in France and in most Western countries currently do not refer to processing of foods ${ }^{(47)}$. Moreover, public health initiatives tend to entice manufacturers to reformulate their products towards healthier compositions and promote innovation of 'healthier' alternatives. However, these alternatives, although nutritionally more appropriate, are still highly processed, yielding high contents of additives or neoformed contaminants ${ }^{(24,47)}$. Disentangling the effects of processing between its nutritional dimension (addition of fat, sugar and sodium) and processing itself (through neoformed contaminants, artificial additives, or the modification of the food structure (matrix effect)) is therefore necessary to build scientifically based and effective strategies towards manufacturers. The inclusion of recommendations pertaining to processing of foods may be a well-founded option if processing itself proves harmful beyond its sole nutritional dimension ${ }^{(47)}$.

To our knowledge, our study is the first to investigate the contribution of UPF in the diet in a French sample. Moreover, we were able to investigate the contribution of the various food groups to UPF consumption in a large sample of subjects with a high adherence to nutritional recommendations. This large number of subjects allowed us to observe a wide range in dietary patterns and to analyse subgroups with sufficient power. Finally, our study relied on dietary data from repeated dietary records, yielding more accurate measures of dietary intakes ${ }^{(30)}$.

Our study is subject to some limitations. First, although the dietary data from the $24 \mathrm{~h}$ records offered a range of more than 3000 food and beverage items, we did not have systematic access to the type of processing involved in the food. Thus, some subjectivity was involved in the classification process of the various foods. As a conservative approach was considered for the classification of foods (i.e. classifying foods for which the category was not obvious into the least processed group), it may have led to an underestimation of the proportion of UPF in the diet. However, as our results were overall consistent with other studies using individual dietary data, the magnitude of this bias can be considered low ${ }^{(7,19,22,23)}$.

A second limitation pertains to the type of classification we selected. Although it offers a good overview of the degree of processing in the diet, it does not take account of the type of processing involved in the manufacturing of the product. However, differing types of processing generate different classes of neo-formed contaminants and therefore different risks on health. The inclusion of this dimension of processing would further enhance our knowledge about the risks entailed by diets rich in UPF.

Finally, our study included volunteers from the general population. Self-selection may have led to the inclusion of individuals more aware of their diets, and therefore with healthier dietary patterns, than in the general population. Indeed, our sample included mainly women, who are known to be more concerned about diet. Thus, it may be hypothesized that the proportion of UPFp would be even higher in the general French population. Caution is therefore needed when considering generalizing our results.

\section{Conclusion}

Our results show that UPF play an important part in the diet in subjects from the French general population. Moreover, they appear important contributors to the diet even in groups with high adherence to nutritional recommendations. UPFp were especially consumed in young individuals with low socio-economic profiles, reflecting socio-economic disparities. Besides, UPFp are associated with unbalanced nutritional intakes. Their regular consumption is suggested to have adverse health consequences that should be further investigated.

\section{Acknowledgements}

Acknowledgements: The authors thank all the volunteers of the NutriNet-Santé cohort. They extend special thanks to Véronique Gourlet, Nathalie Arnault, Stephen Besseau, Laurent Bourhis, Yasmina Chelghoum, Than Duong Van, Younes Esseddik, Paul Flanzy, Charlie Ménard, Mac Rakotondrazafy and Fabien Szabo for their technical contribution to the NutriNet-Santé study. Financial support: The NutriNet-Santé study was supported by the following public institutions: Ministère de la Santé, Institut de Veille Sanitaire (InVS), Institut National de la Prévention et de l'Education pour la Santé (INPES), Fondation pour la Recherche Médicale (FRM), Institut de Recherche en Santé Publique (IRESP), Fondation ARC pour la recherche sur le cancer, Région Ile-de-France (CORDDIM), Institut National de la Santé et de la Recherche Médicale (INSERM), Institut National de la Recherche Agronomique 
(INRA), Conservatoire National des Arts et Métiers (CNAM) and Université Paris 13. The funders had no role in study design, data collection and analysis, decision to publish, or preparation of the manuscript. Study sponsors had no part in study design, collection, analysis, and interpretation of data and the writing of the article and the decision to submit it for publication. Conflict of interest: The authors have no conflict of interest to disclose. Researchers are independent from funders and sponsors. Authorship: C.J. wrote the statistical analysis plan, analysed the data, and drafted and revised the paper. She is the guarantor. L.M., C.M. and E.K.-G. participated in the statistical analysis plan, analysed the data and critically revised the paper for important intellectual content. B.A. and M.T. analysed the data and critically revised the paper for important intellectual content. S.H. designed the data collection tools, implemented the study, monitored data collection for the whole study and critically revised the draft paper for important intellectual content. All researchers had access to all data. All authors have read and approved the final manuscript. Ethics of human subject participation: The NutriNet-Santé study is conducted in accordance with the Declaration of Helsinki, and all procedures were approved by the Institutional Review Board of the French Institute for Health and Medical Research (IRB Inserm no. 0000388FWA00005831) and the Commission Nationale Informatique et Libertés (CNIL no. 908450 and 909216). Electronic informed consent was obtained from all participants (EudraCT registration no. 2013-000929-31).

\section{Supplementary material}

To view supplementary material for this article, please visit https://doi.org/10.1017/S1368980017001367

\section{References}

1. Ng M, Fleming T, Robinson M et al. (2014) Global, regional, and national prevalence of overweight and obesity in children and adults during 1980-2013: a systematic analysis for the Global Burden of Disease Study 2013. Lancet 384, 766-781.

2. Ogden CL, Carroll MD, Kit BK et al. (2014) Prevalence of childhood and adult obesity in the United States, 2011-2012. JAMA 311, 806-814.

3. Monteiro C (2010) The big issue is ultra-processing. World Nutr 1, 237-269.

4. Monteiro CA, Moubarac JC, Cannon G et al. (2013) Ultraprocessed products are becoming dominant in the global food system. Obes Rev 14, 21-28.

5. Weaver CM, Dwyer J, Fulgoni VL et al. (2014) Processed foods: contributions to nutrition. Am J Clin Nutr 99, $1525-1542$.

6. Monteiro C, Cannon G, Levy RB et al. (2016) NOVA. The star shines bright. World Nutr 7, 28-38.

7. Steele EM, Baraldi LG, Louzada MLD et al. (2016) Ultraprocessed foods and added sugars in the US diet: evidence from a nationally representative cross-sectional study. BMJ Open 6, e009892.

8. Poti JM, Mendez MA, Ng SW et al. (2015) Is the degree of food processing and convenience linked with the nutritional quality of foods purchased by US households? Am J Clin Nutr 101, 1251-1262.

9. Luiten CM, Steenhuis IHM, Eyles H et al. (2016) Ultraprocessed foods have the worst nutrient profile, yet they are the most available packaged products in a sample of New Zealand supermarkets. Public Health Nutr 19, 530-538.

10. Institut National de Prévention et d'Education pour la Santé (2002) La santé vient en mangeant. Le guide alimentaire pour tous. Paris: INPES.

11. Institut National de Prévention et d'Education pour la Santé (2004) La santé vient en mangeant et en bougeant. Le guide nutrition des enfants et ados pour tous les parents. Paris: INPES.

12. Ministry of Health of Brazil (2014) Dietary Guidelines for the Brazilian Population, 2nd ed. Brasilia: Virtual Health Library of the Ministry of Health.

13. Tavares LF, Fonseca SC, Rosa MLG et al. (2012) Relationship between ultra-processed foods and metabolic syndrome in adolescents from a Brazilian Family Doctor Program. Public Health Nutr 15, 82-87.

14. Canella DS, Levy RB, Martins APB et al. (2014) Ultraprocessed food products and obesity in Brazilian households (2008-2009). PLoS One 9, e92752.

15. Mendonca RD, Pimenta AM, Gea A et al. (2016) Ultraprocessed food consumption and risk of overweight and obesity: the University of Navarra Follow-Up (SUN) cohort study. Am J Clin Nutr 104, 1433-1440.

16. Louzada MLD, Martins APB, Canella DS et al. (2015) Ultraprocessed foods and the nutritional dietary profile in Brazil. Rev Saude Publica 49, 38.

17. Moodie R, Stuckler D, Monteiro C et al. (2013) Profits and pandemics: prevention of harmful effects of tobacco, alcohol, and ultra-processed food and drink industries. Lancet 381, 670-679.

18. Moreira PVL, Baraldi LG, Moubarac JC et al. (2015) Comparing different policy scenarios to reduce the consumption of ultra-processed foods in UK: impact on cardiovascular disease mortality using a modelling approach. PLOS One 10, e0118353.

19. Moubarac JC, Martins APB, Claro RM et al. (2013) Consumption of ultra-processed foods and likely impact on human health. Evidence from Canada. Public Health Nutr 16, 2240-2248.

20. Birlouez-Aragon I, Morales F, Fogliano V et al. (2010) The health and technological implications of a better control of neoformed contaminants by the food industry. Pathol Biol (Paris) 58, 232-238.

21. Fardet A (2016) Minimally processed foods are more satiating and less hyperglycemic than ultra-processed foods: a preliminary study with 98 ready-to-eat foods. Food Funct 7, 2338-2346.

22. Adams J \& White M (2015) Characterisation of UK diets according to degree of food processing and associations with socio-demographics and obesity: cross-sectional analysis of UK National Diet and Nutrition Survey (2008-12). Int J Behav Nutr Phys Act 12, 160.

23. Louzada MLD, Baraldi LG, Steele EM et al. (2015) Consumption of ultra-processed foods and obesity in Brazilian adolescents and adults. Prev Med 81, 9-15.

24. Monteiro C (2011) The big issue is ultra-processing. There is no such thing as a healthy ultra-processed product (Commentary). World Nutr 2, 333-349.

25. Hercberg S, Castetbon K, Czernichow S et al. (2010) The Nutrinet-Sante Study: a web-based prospective study on the relationship between nutrition and health and determinants of dietary patterns and nutritional status. BMC Public Health 10, 242.

26. Hercberg S, Deheeger M \& Preziosi P (2002) SU.VI.MAX Portions alimentaires. Manuel photos pour l'estimation des quantités. Paris: Editions Polytechnica. 
27. Hercberg S (coordinator) (2005) Table de composition SU.VI.MAX des aliments. Paris: Les éditions INSERM/ Economica.

28. Black AE (2000) Critical evaluation of energy intake using the Goldberg cut-off for energy intake:basal metabolic rate. A practical guide to its calculation, use and limitations. Int J Obes Relat Metab Disord 24, 1119-1130.

29. Lassale C, Peneau S, Touvier M et al. (2013) Validity of webbased self-reported weight and height: results of the Nutrinet-Sante study. J Med Internet Res 15, e152.

30. Lassale C, Castetbon K, Lapote F et al. (2015) Validation of a web-based, self-administered, non-consecutive-day dietary record tool against urinary biomarkers. Br J Nutr $\mathbf{1 1 3}$, 953-962.

31. Lassale C, Castetbon K, Laporte F et al. (2016) Correlations between fruit, vegetables, fish, vitamins, and fatty acids estimated by web-based nonconsecutive dietary records and respective biomarkers of nutritional status. J Acad Nutr Diet 116, 427-438.

32. Touvier M, Kesse-Guyot E, Mejean C et al. (2011) Comparison between an interactive web-based selfadministered $24 \mathrm{~h}$ dietary record and an interview by a dietitian for large-scale epidemiological studies. $\mathrm{Br} J \mathrm{Nutr}$ 105, 1055-1064.

33. Institut National de la Statistique et des Etudes Economiques (2014) Méthodes. https://www.insee.fr/en/information/ 2107769 (accessed June 2017).

34. Craig CL, Marshall AL, Sjostrom M et al. (2003) International physical activity questionnaire: 12-country reliability and validity. Med Sci Sports Exerc 35, 1381-1395.

35. World Health Organization (2000) Obesity: Preventing and Managing the Global Epidemic. Report of a WHO Consultation. WHO Technical Report Series no. 894. Geneva: WHO.

36. Willett W \& Stampfer MJ (1986) Total energy intake: implications for epidemiologic analyses. Am J Epidemiol 124, $17-27$.
37. Estaquio C, Kesse-Guyot E, Deschamps V et al. (2009) Adherence to the French Programme National Nutrition Sante Guideline Score is associated with better nutrient intake and nutritional status. $J$ Am Diet Assoc 109, 1031-1041.

38. United Nations Educational, Scientific and Cultural Organization (2010) Convention for the Safeguarding of the Intangible Cultural Heritage. Intergovernmental Committee for the Safeguarding of the Intangible Cultural Heritage. Fifth Session Nairobi, Kenya. 15 to 19 November 2010. ITH/10/5.COM/CONF.202/6. Paris: UNESCO.

39. Mariotti MS, Granby K, Rozowski J et al. (2013) Furan: a critical heat induced dietary contaminant. Food Funct $\mathbf{4}$, 1001-1015.

40. Friedman M (2003) Chemistry, biochemistry, and safety of acrylamide. A review. I Agric Food Chem 51, 4504-4526.

41. Rice JM (2005) The carcinogenicity of acrylamide. Mutat Res 580, 3-20.

42. Dybing E \& Sanner T (2003) Risk assessment of acrylamide in foods. Toxicol Sci 75, 7-15.

43. Popkin BM \& Gordon-Larsen P (2004) The nutrition transition: worldwide obesity dynamics and their determinants. Int J Obes Relat Metab Disord 28, Suppl. 3, S2-S9.

44. Stuckler D \& Nestle M (2012) Big Food, food systems, and global health. PLoS Med 9, e1001242.

45. Stuckler D, McKee M, Ebrahim S et al. (2012) Manufacturing epidemics: the role of global producers in increased consumption of unhealthy commodities including processed foods, alcohol, and tobacco. PLoS Med 9, e1001235.

46. Scrinis G (2016) Reformulation, fortification and functionalization: Big Food corporations' nutritional engineering and marketing strategies. J Peasant Stud 43, 17-37.

47. Fardet A, Rock E, Bassama J et al. (2015) Current food classifications in epidemiological studies do not enable solid nutritional recommendations for preventing diet-related chronic diseases: the impact of food processing. Adv Nutr 6, 629-638. 